\title{
Detection of Pesticide via Nanoparticle Based Quartz Crystal Microbalance Sensor
}

\section{Nanopartikül Temelli Kuvartz Kristal Mikroterazi Sensör ile Pestisit Tayini}

\author{
Monireh Bakhshpour $^{1}$, Ilgım Göktürk ${ }^{1}$, Oğuz Çakır² ${ }^{2}$ Fatma Yılmaz $^{3}$, Zübeyde Baysal ${ }^{4}$, Adil Denizli ${ }^{3}$ \\ ${ }^{1}$ Department of Chemistry, Hacettepe University, Beytepe, Ankara, Turkey. \\ ${ }^{2}$ Dicle University, Science and Technology Application and Research Center, Diyarbakır, Turkey. \\ ${ }^{3}$ Department of Chemistry Technology, Bolu Abant İzzet Baysal University, Gerede, Bolu, Turkey. \\ ${ }^{4}$ Dicle University, Faculty of Science, Department of Chemistry, Diyarbakır, Turkey.
}

\section{ABSTRACT}

$\mathrm{n}$ this study, chlorpyrifos (Cps) imprinted nanoparticles based QCM sensor were prepared for the detection of chlorpyrifos pesticide. Cps imprinted poly(ethylene glycol dimethacrylate- N- metacryloyl- (L)- tryptophan) (PEDMATrp) nanoparticles were prepared and then these nanoparticles were attached to the surface of QCM sensor chip. Also, nonimprinted PEDMATrp QCM sensor was prepared without using Cps molecule to evaluate the imprinting efficiency. Cps imprinted and non-imprinted nanoparticles were characterized by zeta-sizer and Fourier transform infrared spectrophotometer-attenuated total reflection (FTIR-ATR) spectrophotometer. Cps imprinted and non-imprinted QCM sensors were also characterized by atomic force microscopy, ellipsometer, and contact angle measurements. The prepared sensors were applied for selective Cps detection in aqueous solution for the range of 0.015-2.9 nM. The selectivity studies of the QCM sensor were examined by using competitive pesticide molecules such as diazinon and parathion (2.9 nM), which are similar to Cps in size and shape. The reusability studies of the prepared sensors were investigated by applying the same pesticide concentration (1.45 $\mathrm{nM})$, four times consecutively.

\section{Key Words}

Chlorpyrifos, molecular imprinting, nanoparticles, quartz crystal microbalance.

\section{ÖZ}

\begin{abstract}
u çalışmada, kloropirifos (Cps) baskılanmış nanopartikül temelli QCM sensörü, kloropirifos pestisit tayini için hazırlanmıştır. Cps baskılanmış poli(etilen glikol dimetakrilat-N- metakriloil- (L)- triptofan) (PEDMATrp) nanopartikülleri hazırlandıktan sonra nanopartiküller QCM sensör çipinin yüzeyine tutturuldu. Ayrıca, baskılama etkinliğini değerlendirmek için Cps molekülü kullanılmadan baskılanmamış PEDMATrp QCM sensörü hazırlanmıştır. Cps baskılanmış ve baskılanmamış nanopartiküller zeta-boyut ve FTIR-ATR spektrofotometresi ile karakterize edilmiştir. Cps baskılanmış ve baskılanmamış QCM sensörleri atomik kuvvet mikroskobu, elipsometre ve temas açısı ölçümleri ile karakterize edilmiştir. Hazırlanan QCM sensörler, sulu çözeltide seçici olarak Cps tayini için 0.015-2.9 nM aralığında sinyal vermiştir. Hazırlanan PEDMATrp kuvartz kristal mikroterazi sensörün seçiciliği, Diazinon ve Parathion (2.9 nM) gibi boyut ve şekil bakımından kloropirifosa benzer yarışmacı pestisit molekülleri kullanılarak incelenmiştir. Hazırlanan sensörlerin tekrar kullanılabilirlik çalışmaları aynı pestisit derişiminde (1.45 nM) dört kez art arda uygulanmasıyla gerçekleştirilmiştir.
\end{abstract}

\section{Anahtar Kelimeler}

Kloropirifos, moleküler baskılama, nanopartiküller, kuartz kristal mikroterazi. 


\section{INTRODUCTION}

A natural environment, fruits, vegetables, and waters can be contaminated by a wide variety

of pollutants from agricultural, industrial, and other human activities. Pesticides as environmental pollutants are apprehensive due to their toxicity and the extensive agriculture of their use. In specific, organophosphorus compounds are widely used for agricultural and household aims [1]. Chlorpyrifos (Cps) is an organophosphate pesticide used to kill insects and worms. It acts on the nervous system of insects by inhibiting acetylcholinesterase enzyme. $\mathrm{Cps}\left(\mathrm{C}_{9} \mathrm{H}_{11} \mathrm{Cl}_{3} \mathrm{NO}_{3} \mathrm{PS}\right)$ is broad spectrum of insecticide that used in agriculture to control insect and arthropod pests. Humans can be exposed to Cps molecule which is mostly hazardous by way of ingestion or inhalation. Cps interferes with signaling from the neurotransmitter acetylcholine. Cps-oxon as a Cps metabolite, binds permanently to the enzyme acetylcholinesterase, preventing this enzyme from deactivating acetylcholine in the synapse. Therefore, Cps leads to a collapsing of acetylcholine between neurons and a stronger, longer-lasting signal transfer to the next neuron [2].

Food and agricultural companies need advanced, precise techniques such as sensor technology to ensure the safety of the products. Sensors have important advantages such as short analysis time, remarkable sensitivity when compared to classical analytical methods [3-11]. Quartz crystal microbalance (QCM) is widely used for sensor field studies. QCM as a highly sensitive method can convert a mass change into an electrical signal [12]. The used QCM sensors exhibited high sensitivity and se-lectivity for detection of pesticides $[13,14]$.

Molecular recognition plays a crucial role in biochemical processes in cellular events like cell signaling, cell adhesion and proliferation, apoptosis. Specific interactions between macromolecules, such as antigenantibody, sugar-lectin, receptor-ligand, protein-protein, protein-nucleic acid, are realized through molecular recognition. Non-covalent bonding (hydrogen bonding, van der Waals forces, metal coordination, electrostatic interactions, hydrophobic forces etc.) and geometric conformity contribute to interactions between molecules in biological systems. Thus, natural recognition systems contain multipoint binding and excellent affinity between two or more related macromolecules $[15,16]$. In this study, the molecularly imprinted PEDMATrp nanoparticles attached QCM sensors having high sensitivity and selectivity to Cps molecule were developed. Firstly, Cps imprinted (PEDMATrp) nanoparticles were prepared and then attached to the chip surfaces. The non-imprinted (PEDMATrp) nanoparticles attached PEDMATrp QCM chip was also prepared in the same method without the Cps molecule. Cps imprinted and non-imprinted (PEDMATrp) nanoparticles were characterized by zeta-sizer and Fourier transform infrared spectrophotometer-attenuated total reflection (FTIR-ATR) spectrophotometer measurements. Also, Cps imprinted and non-imprinted (PEDMATrp) nanoparticles attached QCM sensors were characterized using contact angle, ellipsometry, atomic force microscopy (AFM) analyses. The detection efficiency of Cps imprinted PEDMATrp QCM sensor was analyzed by applying aqueous solutions of Cps pesticides. Kinetic parameters were calculated by using Langmuir, Freundlich, Langmuir-Freundlich, Scatchard adsorption isotherm models and association kinetic analysis. In addition, intraday reproducibility of the QCM sensors was tested by applying same Cps solution four times consecutively during the same day.

Herein, a molecularly imprinted (PEDMATrp) nanoparticle based QCM sensor was developed for the determination of Cps in an aqueous solution. LOD, selectivity, sensitivity and reusability of used (PEDMATrp) nanoparticle attached QCM sensor chip system were investigated. The prepared PEDMATrp QCM sensor enables real-time monitoring of $\mathrm{Cps}$ determination in an aqueous solution. The molecularly imprinted (PEDMATrp) nanoparticle based QCM sensor has high selectivity and sensitivity, excellent specificity to $\mathrm{Cps}$ with low LOD value. Cps imprinted and non-imprinted amino acid based (PEDMATrp) nanoparticle coated QCM sensor having dual ability to form both hydrophobic matrix and functional group supplier in one mode were prepared. PEDMATrp QCM sensor was used to detect Cps molecule for the first time without needing any other spacer arm or any extra complicated processes such as ligand immobilization. The PEDMATrp QCM sensor could be a reliable alternative to current techniques to detect Cps molecules and also might play a role in protecting environmental pollution and human health.

\section{MATERIALS and METHODS}

\section{Materials}

Sodium dodecyl sulfate (SDS), poly(vinyl alcohol) (PVA), ammonium persulfate (APS), sodium bisulfite, sodium 
bicarbonate were obtained from Sigma Chemical Co. (St. Louis, USA). The initiator $\alpha, \alpha$-azoisobutyronitrile (AIBN) used in the preparation of nanoparticle is obtained from Fluka A.G. (Buchs, Switzerland).

\section{Preparation of Cps imprinted and non-imprinted nanoparticles}

Cps imprinted (PEDMATrp) nanoparticles were prepared by a two-phase mini-emulsion polymerization method [12]. Here PVmet-A, SDS and sodium bicarbonate were used to preparate of nanoparticles. $100 \mu \mathrm{L}$ MATrp as functional monomer was dissolved in a crosslinker monomer, EGDMA to form oil phase. The oil phase was slowly added to the firstly prepared aqueous phase.

The mixture was homogenized. After homogenization process, the template molecule Cps $(0.01 \mathrm{mmol})$ was added to the homogenized mini-emulsion solution. The obtained mixture was slowly added to the second aqueous phase while the phase has been stirred magnetically at 300 rpm (Radleys Carousel 6, Essex, UK) in a sealed-cylindri-cal polymerization reactor and polymerization mixture was slowly heated until reaching to the polymerizati-on temperature, $40 \circ \mathrm{C}$. Then, initiators, sodium bisul-fite and ammonium persulfate were added into the polymerization mixture solution. Polymerization was continued for $24 \mathrm{~h}$ at 600 rpm stirring rate.

\section{Characterization of Cps imprinted (PEDMATrp) nanoparticles}

Cps imprinted (PEDMATrp) nanoparticles were characterized by using zetasizer. For data analysis, density, viscosity and refraction index of deionized water were used as $1.00 \mathrm{~g} / \mathrm{ml}, 0.88 \mathrm{mPa} \mathrm{s}^{-1}$ and 1.33 , respectively. FTIR-ATR was made for the characterization of the Cps imprinted nanoparticles

\section{Preparation of Cps imprinted and non-imprinted (PEDMATrp) nanoparticles based QCM sensors}

The gold surface of the QCM sensor chips, before immobilized with nanoparticles, must washed with 5 $\mathrm{mL}$ acidic piranha, $5 \mathrm{~mL}$ ethanol and then $5 \mathrm{~mL}$ deionized water, respectively. Then they are pressurized at $200 \mathrm{mmHg}$ and allowed to dry under $37^{\circ}$ C degree. Then, $10 \mu \mathrm{L}$ of Cps imprinted (PEDMATrp) nanoparticles were dropped onto e QCM chip

Figure 1 shows the schematic illustrati-on of Cps binding/rebinding onto the PEDMATrp QCM sensor chip. The PEDMATrp QCM sensor chip was purged. The Cps non-imprinted (PEDMATrp) nanoparticles based QCM sensor chip was also prepared by the same method.

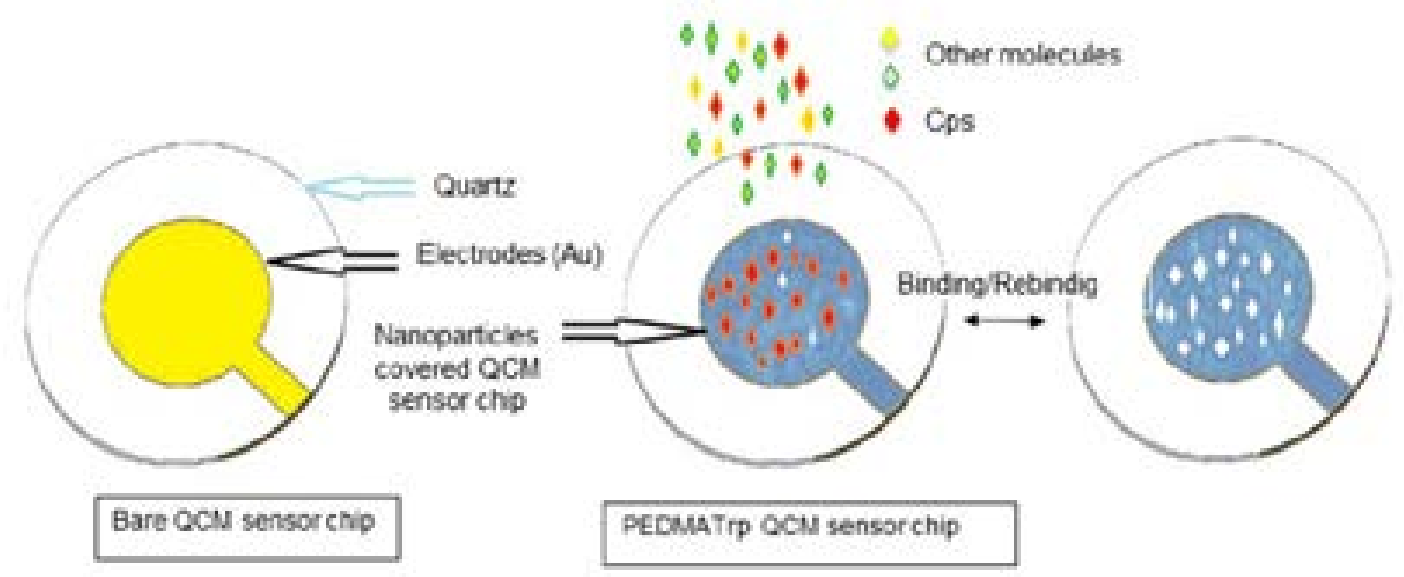

Figure 1. Schematic illustration of Cps binding/rebinding onto the PEDMATrp QCM sensor chip. 


\section{Characterization of Cps imprinted and non-imprinted (PEDMATrp) nanoparticles based QCM sensors}

Atomic force microscopy (AFM), ellipsometer and contact angle measurements were made for the characterization of QCM chips. For the thickness measurements of QCM chips, measurements were taken at $62^{\circ}$ angles and $532 \mathrm{~nm}$ wavelength settings, mean values were recorded. The contact angle measurements were made by the "Sessile drop" method which was used for charac-terization of solid surfaces and based on capturing the image of the dripped liquid. The data of the QCM chip surfaces were taken separately. AFM (Nanomagnetics Instruments, Oxford, UK) was used in a tapping mode to evaluate surface topography of QCM chips.

\section{Kinetic analyses of Cps imprinted and non-imprinted (PEDMATrp) nanoparticles QCM sensors}

After the preparation of Cps imprinted (PEDMATrp) nanoparticles based QCM sensors, kinetic studies are started by using an RQCM (Maxtek) software. The Cps detection was performed by Cps imprinted and nonimprinted (PEDMATrp) nanoparticles QCM chips. Firstly, PEDMATrp QCM chips were equilibrated with $0.1 \mathrm{M}$ phosphate buffer ( $\mathrm{pH}$ 5.5). Then, Cps (0.015-2.9 nM) was applied to the PEDMATrp QCM sensor systems. Then, to form cavities, $0.1 \mathrm{M}$ acetic acid and $0.1 \mathrm{M}$ $\mathrm{CaCl}_{2}$ solutions were applied respectively for removing Cps pesticide. Freundlich, Langmuir, and Langmuir-Freundlich adsorption isotherm models were examined to detect the equilibrium isotherm parameters.

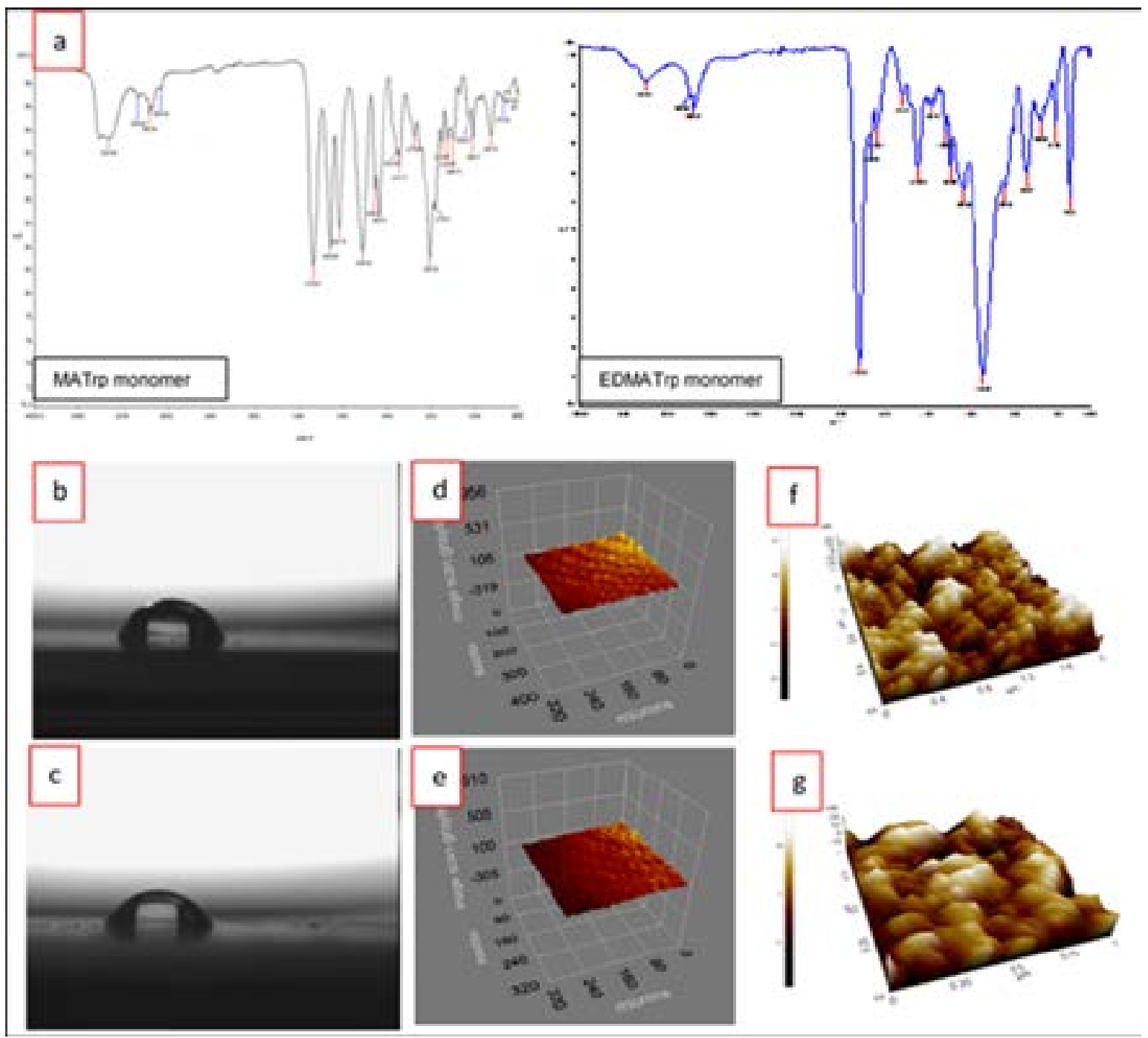

Figure 2. FTIR-ATR spectrum of MATrp and EDMATrp monomer (a). Morphological characterization of the bare gold chip and Cps imprinted PEDMATrp QCM sensor surfaces (contact angles; b. bare gold surface, c. Cps imprinted PEDMATrp QCM sensor chip). AFM studies; d. Cps imprinted PEDMATrp QCM sensor chip, e. non-imprinted PEDMATrp QCM sensor chip. Ellipsometry images; f. Cps imprinted PEDMATrp QCM sensor chip, g. non-imprinted PEDMATrp QCM sensor chip. 


\section{Selectivity and repeatability analyses of the PEDMATrp QCM sensors}

Diazinon and parathion $2.9 \mathrm{nM}$ were used as competitive molecules for selectivity studies of the PEDMATrp QCM sensors. Diazinon and parathion pesticides which are similar to Cps in both molecular structure and weight was used in studies of the selectivity.

Studies of reusability were obtained with $\mathrm{pH} 5.5$ buffer for 5 minutes, then the same concentration of sample was passed for 10 minutes and finally the desorption solution was passed for 5 minutes. The reusibility of QCM sensor was repeated 4 times.

\section{RESULTS and DISCUSSION}

\section{Characterization of Cps imprinted and non-imprinted (PEDMATrp) nanoparticles}

The synthesized (PEDMATrp) nanoparticles were characterized by the zeta-sizer. Cps imprinted (PEDMATrp) nanoparticles have an average particle size of $84.62 \mathrm{~nm}$ with a low polydispersity index of 0.12 . The nonimprinted nanoparticles also have similar physical and chemical properties with $80.72 \mathrm{~nm}$ average particle size and 0.14 polydispersity index value. FTIR-ATR spectrophotometer (Figure 2a) was chosen for characterization of Cps imprinted and non-imprinted nanoparticles.

\section{Characterization of Cps imprinted and non-imprinted (PEDMATrp) nanoparticles based QCM chips}

The surfaces of the bare gold chip as blank, QCM chips were characterized after modification steps by contact angle, AFM and ellipsometry measurements. As shown in Figure 2b, 2c, contact angle values were obtained to be $82.2^{\circ} \pm 1.18$ and $63.4^{\circ} \pm 2.05$ for both gold surface,

Cps imprinted and non-imprinted PEDMATrp QCM sensors, respectively. If the contact angle is greater than 90 degrees.
It can be said that surface is hydrophobic. The decrease of the contact angle values is due to the attachment of the amino acid based functional monomers to a gold surface.

The thickness of the Cps imprinted and non-imprinted PEDMATrP QCM sensor chip surfaces were measured by ellipsometry and shown in Figure 2d, 2e. Thickness measurements that are controlling the specificity, selectivity and recognition rate of the sensors were recorded as $95.3 \pm 0.34$ for non-imprinted, and $84.8 \pm 0.92 \mathrm{~nm}$ for imprinted QCM sensor.

The AFM images displayed that Cps imprinted and non-imprinted PEDMATrp QCM chip surfaces have $65.3 \pm 0.34$, and $67.8 \pm 0.92 \mathrm{~nm}$ deepness values respectively (Figure $2 \mathrm{f}, 2 \mathrm{~g}$ ). Ellipsometer results which are consistent with AFM results emphasize that Cps imprinted and non-imprinted PEDMATrp QCM sensor chips have homogeneous.

\section{Detection of Cps by PEDMATrp QCM sensor} Here, Cps solution was prepared in $\mathrm{pH} 5.5$ phosphat buffer solutions at 0.015-2.9 nM concentrations. The Figure 3a shown the sensorgrams of experiments. The buffer solution at $5.5 \mathrm{pH}$ was applied through the QCM system for 5 minutes, tsecondly the sample solutions was applied to the QCM system for 10 minutes, and then the desorption solution was applied to the system for 5 minutes.

Cps imprinted and non-imprinted PEDMATrp QCM sensors have the linearity of $96 \%$. Therefore, there is a direct correlation between the applied Cps aqueous solution concentrations and the sensors surfaces interacted.

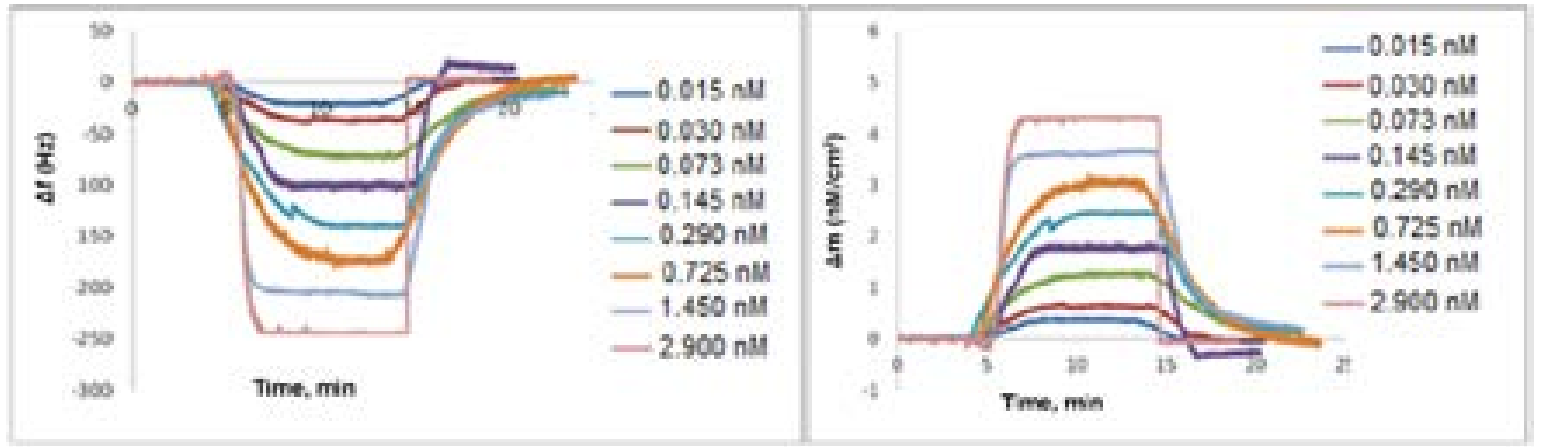

Figure 3. Effect of the applied Cps concentration to the Cps imprinted PEDMATrp QCM sensor. 
Table 1. Langmuir, Freundlich and Langmuir/Freundlich adsorption isotherm models.

\begin{tabular}{llllll}
\hline \multicolumn{1}{c}{ Langmuir } & \multicolumn{2}{c}{ Freundlich } & \multicolumn{2}{c}{ Langmuir- Freundlich } \\
\hline$\Delta \mathrm{m}_{\max }, \mathrm{nM} / \mathrm{cm}^{2}$ & 3.484 & $\Delta \mathrm{m}_{\max ,} \mathrm{nM} / \mathrm{cm}^{2}$ & 3.401 & $\Delta \mathrm{m}_{\max }, \mathrm{nM} / \mathrm{cm}^{2}$ & 5.917 \\
\hline $\mathrm{K}_{\mathrm{A}}, \mathrm{nM}^{-1}$ & 8.969 & $1 / \mathrm{n}$ & 0.431 & $1 / \mathrm{n}$ & 0.431 \\
\hline $\mathrm{K}_{\mathrm{D}}, \mathrm{nM}$ & 0.111 & $\mathrm{R}^{2}$ & 0.942 & $\mathrm{~K}_{\mathrm{A}}, \mathrm{nM}^{-1}$ & 0.447 \\
\hline $\mathrm{R}^{2}$ & & & $\mathrm{~K} \mathrm{~K}_{\mathrm{D}}, \mathrm{nM}$ & 2.237 \\
\hline & & & $\mathrm{R}^{2}$ & 0.952 \\
\hline
\end{tabular}

The Langmuir, Freundlich, and Freundlich-Langmuir isotherms were calculated to obtained the adsorption model for QCM sensor system. The dates of isotherms were shown in Table 1 . This result proves that the surface is homogeneous and there are no lateral interactions between adjacent ad-sorbed template Cps molecules. The standard deviation and slope values are determined from the calibration graph and the limit of detection was calculated. $L O D=3 \times s / b$ equation was used for the limit of detection. The $s$ value used in this equations is the standard deviati-on obtained from the calibration graph, and the $b$ value is also the slope of this graph. LOD value was found as $0.010 \mathrm{nM}$.

\section{Selectivity and repeatability analyses of the PEDMATrp QCM sensors}

Diazinon and parathion (2.9 nM) were used as competitor molecules for selectivity studies of the PEDMATrp QCM sensors. The obtained $\Delta \mathrm{m}$ values were used for the calculation of selectivity coefficients.

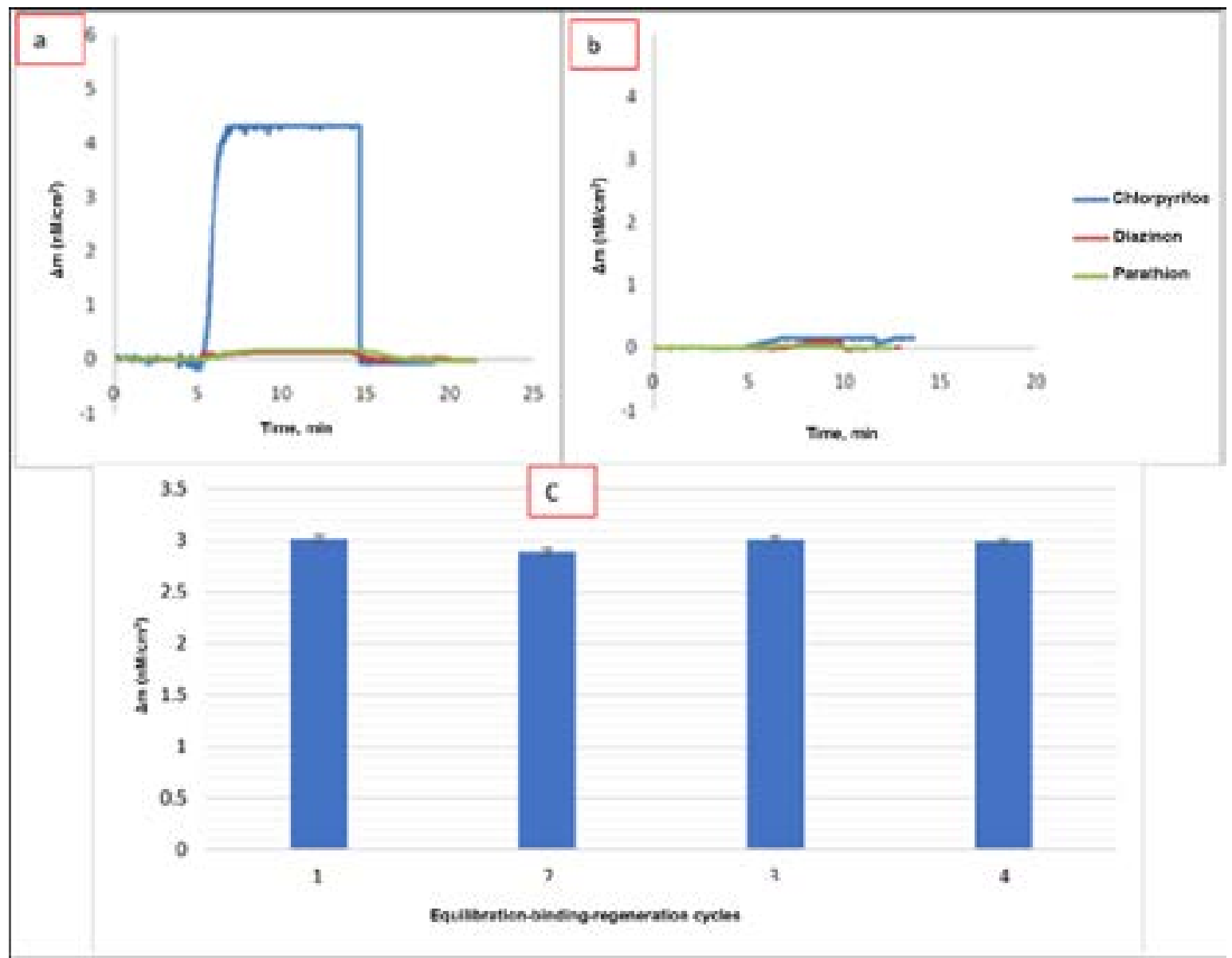

Figure 4. Comparison of selectivity efficiency of PEDMATrp QCM sensors: a. Cps imprinted PEDMATrp QCM sensor, b. Cps non-imprinted PEDMATrp QCM sensor, c. reproducibility of Cps imprinted PEDMATrp QCM sensors. 
Table 2. Selectivity parameters of the PEDMATrp QCM sensors.

\begin{tabular}{|c|c|c|c|c|c|}
\hline \multirow{2}{*}{ MIP } & & & NIP & Langmuir & Langmuir \\
\hline & $\Delta \mathrm{m}$ & k & $\Delta \mathrm{m}$ & k & $k^{\prime}$ \\
\hline Cps & 4.315 & - & 0.089 & - & - \\
\hline Diazinon & 0.134 & 32.201 & 0.071 & 1.253 & 25.699 \\
\hline Parathion & 0.168 & 25.684 & 0.052 & 1.711 & 15.011 \\
\hline
\end{tabular}

The selectivities of the Cps imprinted and nonimprinted PEDMATrP QCM sensor chips against Cps molecule were visualized to emphasize the imprinting process efficiency by recording Cps molecule responses (Figure $4 a, b)$. Selectivity coefficient (k) and relative selectivity coefficient ( $\left.k^{\prime}\right)$ of the prepared QCM sensor were determined by subtracting from the 1st and 2nd equations and shown in Table 2.

$\mathrm{k}=\Delta \mathrm{m}_{\mathrm{cps}} / \Delta \mathrm{m}_{\text {competior }}$

$k^{\prime}=k_{M I P} / k_{N I P}$

These data imply that the sensor surfaces recognize the Cps molecule with a high affinity ability owing to the obtained recognition cavities by molecular imprin-ting of Cps. In the reusability study, Cps solution in $\mathrm{pH} 5.5$ buffer at a concentration of $1.45 \mathrm{nM}$ was given to the system. After passing through the buffer system, the sample was given for about 5 minutes. Then 10 minutes the desorption solution was passed, the same procedure was repeated 4 times and shown in Figure $4 c$. As shown in the figure, almost the same $\Delta m$ value was obtained for each repeated sample.

\section{Conclusion}

For this aim, MATrp monomer which was selected as a proper functional monomer was polymerized with EDMA. Cps imprinted PED-MATrp nanoparticles were used to cover gold surfaces of QCM sensor chips and were characterized. Kinetic and affinity binding of Cps to PEDMATrP QCM sensor was investigated by binding of Cps molecule to Cps imprinted QCM sensor chips.In addition, adsorption kine-tics were determined by passing Cps solutions through PEDMATrp QCM sensor at different concentrations.
The most proper adsorption model for the Cps molecule as an affinity system was found to be Langmuir isotherm model which is assuming that there is no lateral inte-raction between adjacent adsorbed molecules when a single molecule occupies a single surface site. These results proved that the prepared polymeric surfaces were highly desirable for sensitive recognition of QCM sensors for Cps detection.

\section{References}

1. D.S. Sharp, B. Eskenazi, R. Harrison, P. Callas, A.H. Smith, Delayed health hazard of pesticide exposure, Am. J. Public Health, 7 (1986) 441-471.

2. T.A. Slotkin, Developmental cholinotoxicants: nicotine and chlorpyrifos, Environ. Health Perspect., 107 (1999) 71-80.

3. Y.C. Chen, J.J. Brazier M.D. Yan, P.R. Bargo, S.A. Prahl, Flourescence-based optical sensor design for molecularly imprinted polymers, Sensor Actuat. B-Chem., 102 (2004) 107-116.

4. O.P. Luzardo, M. Almeida-González, N. Ruiz-Suárez, M. Zumbado, L.A. Henríquez-Hernández, M.J. Meilán, M. Camacho, L.D. Boada, Validated analytical methodology for the simultaneous determination of a wide range of pesticides in human blood using GC-MS/MS and LC-ESI/ $\mathrm{MS} / \mathrm{MS}$ and its application in two poisoning cases, Sci. and Justice, 55 (2015) 307-315.

5. B. Gabrieli, K. Magali, R. Lucila, B.A. Martha Z. Renato, D.P. Osmar, An effective method for pesticide residues determination in tobacco by GC-MS/MS and UHPLC-MS/ MS employing acetonitrile extraction with low-temperature precipitation and d-SPE clean-up, Talanta, 161 (2016) 40-47.

6. A. Kouzayha, A.R. Rabaa, M. Iskandarani, D. Beh, H. Budzinski, F. Jaber, Multiresidue method for determination of 67 pesticides in water samples using solid-phase extraction with centrifugation and gas chromatography-Mass spectrometry, Am. J. Anal. Chem., 3 (2012) 257-265. 
7. E. Mauriz, A. Calle, L.M. Lechuga, J. Quintana, A. Montoya, J.J. Manclús, Real-time detection of chlorpyrifos at part per trillion levels in ground, surface and drinking water samples by a portable surface plasmon resonance immunosensor, Anal. Chim. Acta, 561 (2006) 40-47.

8. O. Cakır, M. Bakhshpour, F. Yılmaz, Z. Baysal, Novel QCM and SPR sensors based on molecular imprinting for highly sensitive and selective detection of 2,4dichlorophenoxyacetic acid in apple samples, Mater. Sci. Eng. C, 102 (2019) 483-491.

9. M. Calısır, M. Bakhshpour, H. Yavuz, A. Denizli, HbA1c detection via high-sensitive boronate based surface plasmonresonance sensor, ensor Actuat. B-Chem., 306 (2020) 127561-69.

10. S. Akgönüllü, D.Battal, M.S. Yalcin, H. Yavuz, A. Denizli, Rapid and sensitive detection of synthetic cannabinoids JWH-018, JWH-073 and their metabolites using molecularly imprinted polymer-coated QCM nanosensor in artificial saliva, Microchem. J, 153, (2020) 104454.

11. Y. Saylan, A. Denizli, Virus detection using nanosensors, Nanosensors for Smart Cities, (2020) 501-511.
12. N. Kim, I.S. Park, D.K. Kim, High-sensitivity detection for model organophosphorus and carbamate pesticide with quartz crystal microbalance-precipitation sensor, Biosens. Bioelectron., 22 (2007) 1593-1599.

13. M. Bakhshpour, A.K. Piskin, H. Yavuz, A. Denizli, Quartz crystal microbalance biosensor for label-free MDA MB 231 cancer cell detection via notch-4 receptor, Talanta, 204 (2019) 840-845.

14. M. Bakhshpour, E. Özgür, N. Bereli, A. Denizli, Microcontact imprinted quartz crystal microbalance nanosensor for protein C recognition, Colloids and surfaces. B, 151 (2017) 264-270.

15. Y. Saylan, A. Denizli, Molecular fingerprints of hemoglobin on a nanofilm chip, Sensors 18 (2018) 3016.

16. G. Sener, L. Uzun, R. Say, A. Denizli, Use of molecular imprinted nanoparticles as biorecognition element on surface plasmon resonance sensor, Sensor Actuat. B-Chem., 160 (2011) 791-799. 